\title{
Does spontaneous respiration alter pulmonary artery input impedance?
}

\author{
P. Castiglioni*, M. Di Rienzo*, M. Grossoni**, R. Tommasini**, M. Morpurgo**
}

Does spontaneous respiration alter pulmonary artery input impedance? P. Castiglioni, M. Di Rienzo, M. Grossoni, R. Tommasini, M. Morpurgo. CERS Journals Ltd 1996. ABSTRACT: The aim of this study was to determine whether spontaneous respiration influences pulmonary artery input impedance, a question that has received little attention in the literature.

Impedance values were assessed during three different phases of the respiratory cycle, namely inspiration, expiration and postexpiration (i.e. the null respiratory flow period between expiration and the next inspiration) in five anaesthetized spontaneously breathing dogs. Firstly, impedance values during postexpiration were taken as the reference baseline, and compared with values obtained during inspiration and expiration. Then, differences between values in inspiration and in expiration were tested, taking impedance during inspiration as the baseline.

Differences with respect to postexpiration were found for three parameters of input impedance: input resistance, characteristic impedance, and the frequency at the first zero-crossing of the impedance phase from negative to positive values ( $f$ cross). Input resistance was significantly lower in inspiration $(85 \%$ of the baseline), characteristic impedance was significantly greater in inspiration and in expiration (112 and $119 \%$ respectively), and $f$ cross was significantly lower in expiration $(89 \%)$. By contrast, only input resistance differed significantly when inspiration was compared to expiration.

Therefore, spontaneous respiration was shown to influence input impedance significantly. The observed changes in characteristic impedance and $f$ cross might be explained by a stiffening of the pulmonary artery wall, due to neural and/or mechanical factors, during inspiration and expiration.

Eur Respir J., 1996, 9, 2328-2334.
*LaRC-Centro di Bioingegneria, Milan, Italy. **Divisione di Cardiologia, Ospedale S. Carlo Borromeo, Milan, Italy.

Correspondence: P. Castiglioni LaRC-Centro di Bioingegneria via Gozzadini 7 20148 Milan

Italy

Keywords: Characteristic impedance input impedance

pulmonary arterial pressure

pulmonary blood flow

pulmonary circulation

Received: May 291995

Accepted after revision May 31996
It is well-known that pulmonary blood pressure, volume and flow change during each breath. Furthermore, our group [1] has previously shown significant changes in right ventricular systolic time intervals in spontaneously breathing dogs, when inspiration and expiration were compared to the expiratory phase of null respiratory flow. These findings may result not only from a direct respiratory effect on the right ventricle, but also by respiratory influences on pulmonary vessels, which indirectly modulate right heart dynamics through changes in pulmonary artery input impedance. However, whilst data have been gathered on the influence of respiration on pulmonary artery input impedance in mechanically-ventilated animals [2, 3], little information is available concerning possible impedance changes induced by spontaneous respiration. Such information is important, firstly, because in the pulmonary circulation pulsatile power accounts for a large fraction of the total right ventricular external power; and, secondly, because from changes in input impedance it may be possible to evaluate respiratory influences on geometric and mechanical properties of the pulmonary vascular bed.

Having found no significant differences between inspiration and expiration in pulmonary vascular resistance, characteristic impedance and overall impedance spectra in subjects free of cardiopulmonary disease, MurGo and WESTERHOF [4] concluded that quiet respiration has no effect on the pulmonary artery load, and that changes in pressure and flow must result from changes in right ventricular performance. In 1986, WIELAND et al. [5] compared inspiration and expiration, and noted that in patients with coronary disease only low frequency components of impedance were altered by respiration. However, in a subsequent paper, the same group of investigators concluded that "there is no significant respiratory variation in impedance spectra either at rest or during exercise" [6]. Finally, in his fundamental book "Hemodynamics", MILNOR [7] states that "...total pulmonary vascular resistance increases slightly with inspiration, but no respiratory change in pulmonary vascular impedance has been reported".

In our opinion, however, the effects of spontaneous respiration on pulmonary artery input impedance have been incompletely described in previous studies, since a mere comparison between inspiration and expiration was made. The aim of the present work was to investigate more completely whether, and to what extent, spontaneous respiration alters input impedance by considering also the phase of null respiratory flow. This was carried out on anaesthetized, spontaneously breathing dogs by 
considering the postexpiratory phase as a reference condition and by evaluating impedance changes during inspiration and expiration with respect to the reference.

\section{Material and methods}

\section{Animal preparation, data acquisition and preprocessing}

Data were derived from five mongrel dogs. Anaesthesia was induced by pentobarbital sodium $\left(25-30 \mathrm{mg} \cdot \mathrm{kg}^{-1} i . v\right.$. bolus $+0.07 \mathrm{mg} \cdot \mathrm{kg}^{-1} \mathrm{~min}$ infusion). Dogs were turned onto their right sides on a surgical table and intubated. Spontaneous respiration was maintained throughout the experiments. Pulmonary arterial pressure $(\mathrm{Ppa})$ and blood flow velocity $\left(Q^{\prime}\right)$ were obtained by high-fidelity MikroTip catheter (SVPC-684A, 8F; Millar Instr.) with pressure and velocity sensors at the same location. The tip of the catheter was advanced to the main pulmonary artery via the right jugular vein. Respiratory flow was measured by a heated mesh-screen pneumotachograph. All the signals were sampled at $200 \mathrm{~Hz}$ and digitized through a $\mathrm{HP}$ analogue-to-digital converter (HP 6942A). The average duration of each recording was $80.8 \mathrm{~s}$.

The quality of the recordings was checked by visual inspection of $P \mathrm{pa}, Q^{\prime}$ and respiratory signals. In one animal, the shape of the $Q^{\prime}$ signal indicated an incorrect placement of the tip of the catheter and the recording was repeated. In order to identify the single heart beats, the "foot" of each P pa wave was detected as the starting point of the systolic upstroke. Duration of each beat was defined as the time interval between the "foot" of the relevant $P$ pa wave and the "foot" of the following wave. The instantaneous heart rate of the beat, $f \mathrm{C}$, was computed as the reciprocal of the beat duration. Three different respiratory phases were considered: inspiration (I) and expiration $(\mathrm{E})$, identified, respectively, by a positive and a negative respiratory flow trace; and postexpiration $(\mathrm{P})$, defined by the plateau between $\mathrm{E}$ and I (null respiratory flow). Each respiratory cycle was defined by a sequence of $\mathrm{P}, \mathrm{I}$ and $\mathrm{E}$. Based on this procedure, the number of respiratory cycles that were used for the subsequent analysis in dogs Nos. 1-5 were 7, 12, 39, 11 and 7 , respectively.

\section{Beat-to-beat evaluation of impedance}

For each heart beat, mean values and harmonic components of $P$ pa and $Q^{\prime}$ were computed by Fourier analysis. Input resistance $(R \mathrm{I})$, i.e. input impedance $Z(f)$ at $\mathrm{f}=0$ $\mathrm{Hz}$, was obtained by computing the ratio between mean values of $P$ pa and $Q^{\prime}$. To evaluate $Z(f)$ at frequencies greater than $0 \mathrm{~Hz}$, a high signal-to-noise ratio is necessary both for $P$ pa and $Q^{\prime}$ signals over the frequency band where impedance is assessed. For this reason $Z(f)$ was evaluated only in animals having a sufficiently high squared coherence modulus, $\left(|\mathrm{k}(f)|^{2}\right)$ between $P$ pa and $Q^{\prime}$. Firstly, $P$ pa and $Q^{\prime}$ spectra and cross-spectrum were estimated over the whole recording, and $|\mathrm{k}(f)|^{2}$ was then computed as the ratio between the squared cross-spectrum modulus and the product of the two spectra [8]. Recordings having $|\mathrm{k}(f)|^{2}$ greater than 0.8 , at least up to $12 \mathrm{~Hz}$, were considered suitable for evaluation of $Z(f)$. This requirement was met in four of five recordings. For the discarded signal, in which $|\mathrm{k}(f)|^{2}$ was high only up to $6 \mathrm{~Hz}$, long periods of $\mathrm{P}$ were followed by a sequence of I and $\mathrm{E}$ deeper than in the other recordings. This pattern may have resulted in a nonlinear relationship between $P$ pa and $Q^{\prime}$.

For each beat, the input impedance modulus, $|Z(f)|$, and the phase $(\varnothing[Z(f)])$ were evaluated at frequencies equal to the first eight multiples of the instantaneous heart rate, $f \mathrm{C}$. Modulus and phase at $f=\mathrm{n} f \mathrm{C}(\mathrm{n}=1, \ldots, 8)$ were computed as ratios and differences between $P$ pa and $Q^{\prime}$ nth harmonics, respectively [7]. The characteristic impedance modulus (ZC) (i.e. input impedance modulus in the absence of reflected waves) has been estimated in each heart beat by averaging the impedance modulus between 2 and $12 \mathrm{~Hz}$ [9]. Values of $\varnothing[Z(f)]$ at multiples of the instantaneous heart rate, $f \mathrm{C}$, were interpolated by cubic splines to estimate $f$ cross, defined as frequency of the first zerocrossing of $\varnothing[Z(f)]$ from negative to positive values.

\section{Statistical analysis}

Only beats that fell entirely into an individual respiratory phase were considered; i.e. into $\mathrm{P}, \mathrm{I}$ or $\mathrm{E}$. In each animal, $P$ pa, $Q^{\prime}$ and $f \mathrm{C}$ were separately averaged in $\mathrm{P}, \mathrm{I}$ and $\mathrm{E}$, and differences between these three respiratory phases were statistically tested by a two-factor (phases per subjects) analysis of variance (ANOVA). When a significant between-phases difference was found, comparisons between pairs of phases were made by using a paired t-test, modified by the HoLm [10] procedure.

A statistical evaluation of impedance changes was performed on four significant parameters derived from $Z(f)$, namely $R \mathrm{I}, Z \mathrm{C}, f_{\text {cross }}$ and $\left|Z_{1}\right|$, the latter defined as the modulus of impedance at the frequency of the first harmonic, fC. For each respiratory cycle RI, $|Z 1|, Z C$ and $f$ cross were separately evaluated in $\mathrm{P}, \mathrm{I}$ and $\mathrm{E}$. The $\mathrm{P}$ phase was taken as the baseline and compared with I and with $\mathrm{E}$ in each breath. First $R \mathrm{I},\left|Z_{1}\right|, Z_{\mathrm{C}}$ and $f_{\text {cross }}$ in I were expressed as percentage of the corresponding values in the $\mathrm{P}$ phase of the same breath. Respiratory cycles not having at least one beat entirely falling into $\mathrm{P}$ and one entirely falling into I were not considered. Impedance parameters in E were similarly expressed as percentage of values in $\mathrm{P}$. This normalization procedure allowed possible sources of variability other than respiration, such as between-animals' variability and slow variability components with period longer than the respiratory cycle, to be removed. For each animal, percentage variations in I and in $\mathrm{E}$ were log-transformed to obtain sample distributions which approximate the normal distribution, and averaged over all the respiratory cycles to increase reliability. Respiratory influences on $R \mathrm{I},|Z 1|, Z \mathrm{C}$ and $f_{\text {cross }}$ were separately tested by evaluating whether percentage variations in I and in E differ from the $100 \%$ reference values in $\mathrm{P}$, with $\mathrm{p}$-values less than 0.05 considered to be significant. The Hotelling $\mathrm{T}^{2}$ test [11] was used, which is an extension of the one-sample t-test to multiple comparisons.

Furthermore, differences between inspiration and expiration were also tested, taking I as the baseline and similarly comparing I with $\mathrm{E}$. This was done to emphasize possible differences between the two active phases of the respiratory cycle.

For all tests, a p-value $<0.05$ was considered significant. 


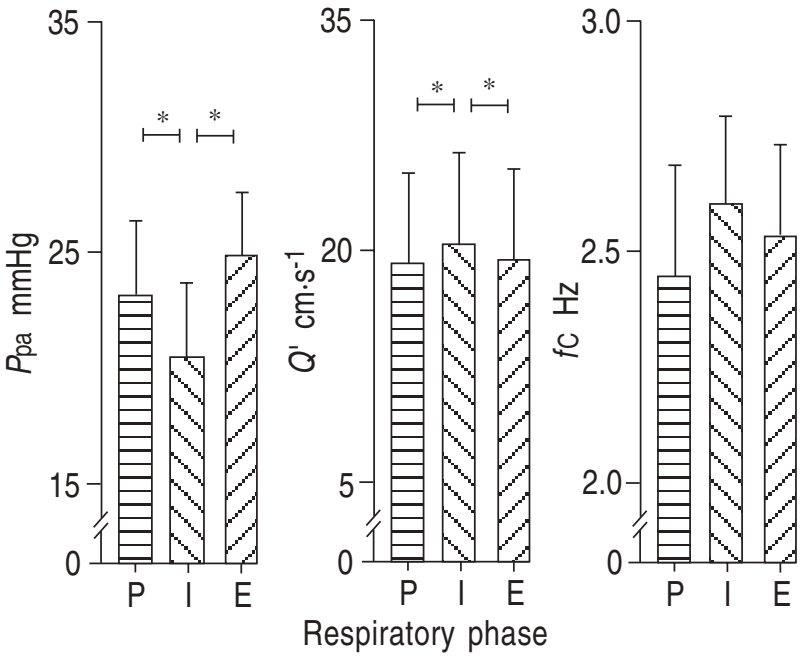

Fig. 1. - Average values and SEM of $P$ pa, $Q^{\prime}$ and $f$ C for beats completely occurring in $\mathrm{P}$, in I and in E. Comparisons between pairs of respiratory phases (modified paired t-test) have been made where twofactors analysis of variance revealed significant differences among the three phases at a significance level of $\mathrm{p}<0.05$, i.e. for $P$ pa and $Q^{\prime}$. ** $\mathrm{p}<0.05$. $P$ pa: pulmonary arterial pressure; $Q^{\prime}$ : flow velocity of blood; $f_{C}$ : instantaneous heart rate; I: inspiration; E: expiration; P: postexpiration (plateau between $\mathrm{E}$ and $\mathrm{I}$, with null respiratory flow).

\section{Results}

Figure 1 shows $P$ pa, $Q^{\prime}$ and $f C$ (mean \pm SEM) in $\mathrm{P}, \mathrm{I}$ and $\mathrm{E}$ for the group of five animals. There were significant differences $(\mathrm{p}<0.05)$ between the three respiratory phases for $P$ pa and $Q^{\prime}$. In particular, a significant decrease of $P$ pa and a significant increase of $Q^{\prime}$ was observed in I when it was compared either to $\mathrm{P}$ or to $\mathrm{E}$. In contrast, no significant differences were observed between $\mathrm{P}$ and E, both for $P$ pa and $Q^{\prime}$.

Figure 2 is an example of beat-to-beat evaluation of $R \mathrm{I}$ and ZC versus the respiratory flow. Only beats completely
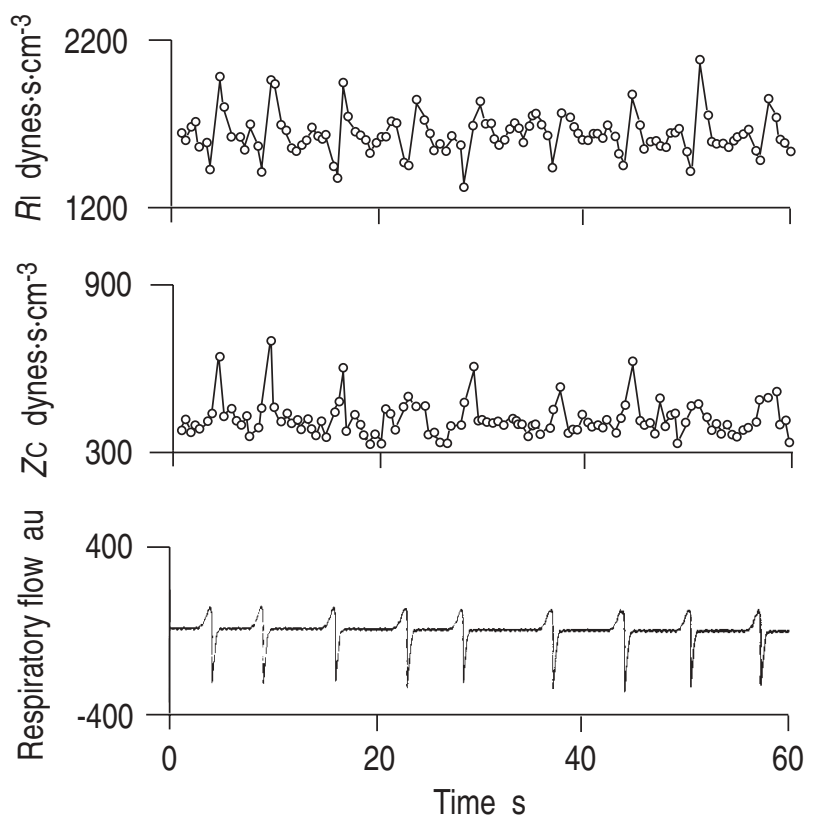

Fig. 2. - Beat-by-beat evaluation of $R \mathrm{I}$ and $\mathrm{ZC}$ along with the respiratory flow in one animal. Only values for beats falling completely into a single respiratory phase are plotted. $R \mathrm{I}$ : input resistance; ZC: characteristic impedance modulus; au: arbitrary unit.
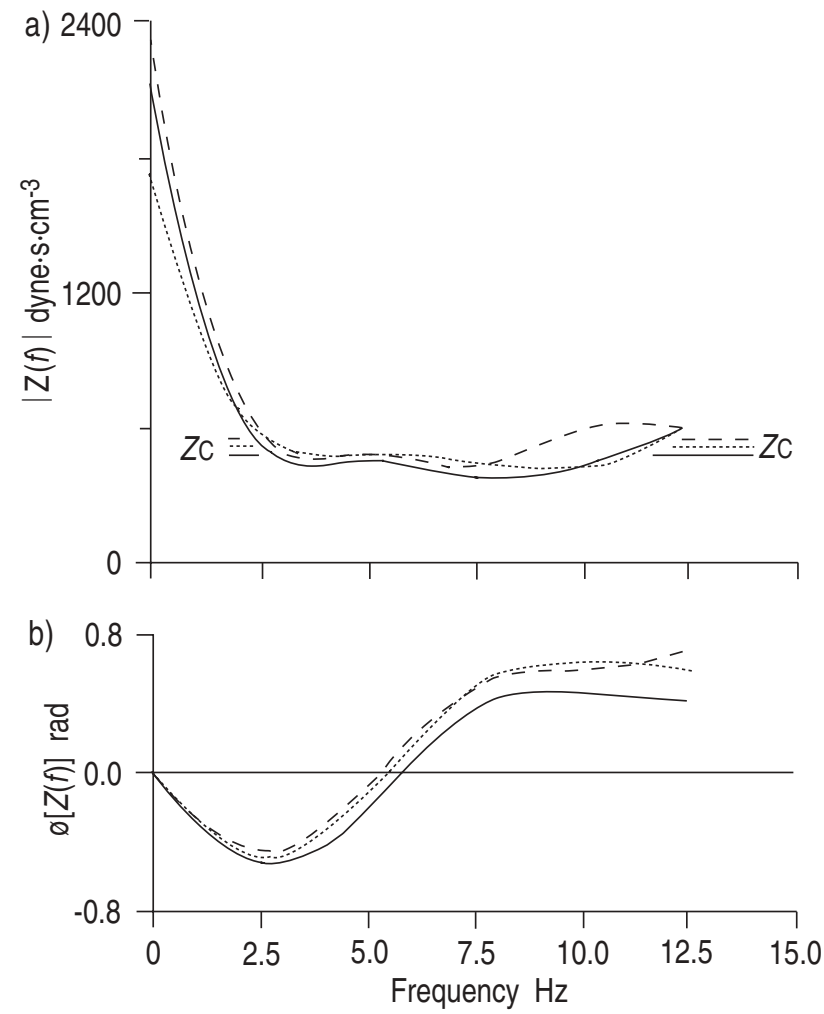

Fig. 3. - a) Input impedance $(Z(f))$ modulus; and b) phase, separately averaged for beats completely occurring during inspiration (I) (……....), expiration (E) (------), and null respiratory flow postexpiration $(\mathrm{P})$ $(\longrightarrow)$. Mean characteristic impedance $\left(Z_{C}\right)$, in $\mathrm{I}, \mathrm{E}$ and $\mathrm{P}$ is also shown. The figure is obtained by interpolation from beat-by-beat impedances at multiples of $2.5 \mathrm{~Hz}$, the mean heart rate over the group of animals, by averaging the interpolated values and by connecting them with spline functions.

falling into one of the three respiratory phases have been plotted. Visual inspection of these tracings suggested the existence of impedance fluctuations synchronous with respiration in all animals.

Figure $3 \mathrm{a}$ shows mean $\mathrm{ZC},|\mathrm{Z}(f)|$ and figure $3 \mathrm{~b}$ the mean $\varnothing[Z(f)]$, for the whole group of animals. Values are separately plotted for P, I and E. Only beats completely falling into a single respiratory phase were considered.

The mean values and the relevant standard deviations for $R \mathrm{I},\left|Z_{1}\right|, Z \mathrm{C}$ and $f_{\text {cross }}$ are reported in table 1 while the variations of the same four parameters during I and $\mathrm{E}$ with respect to $\mathrm{P}$ are shown in table 2 for each animal. From the graphs of figure 3 and data contained in

Table 1. - $A,\left|Z_{1}\right|$ and $Z \mathrm{C}$ in $\mathrm{P}, \mathrm{I}$ and $\mathrm{E}$

\begin{tabular}{lrrrrr}
\hline & $\mathrm{P}$ & \multicolumn{1}{c}{$\mathrm{I}$} & \multicolumn{1}{c}{$\mathrm{E}$} & $\mathrm{n}$ \\
\hline$R \mathrm{I}$ dyn $\cdot \mathrm{s} \cdot \mathrm{cm}^{-3}$ & $2161(1134)$ & $1774(894)$ & $2375(1387)$ & 5 \\
$|Z 1|$ & $587(453)$ & $627(226)$ & 640 & $(187)$ & 4 \\
$Z \mathrm{C}$ dyn $\cdot \mathrm{s} \cdot \mathrm{cm}^{-3}$ & $454(160)$ & $494(147)$ & 520 & $(133)$ & 4 \\
$f_{\text {cross Hz }}$ & $6.42(2.53)$ & $5.56(1.42)$ & $5.48(1.64)$ & 4 \\
\hline
\end{tabular}

Average values are presented and SD in parenthesis. $R \mathrm{I}$ : input resistance; $\left|Z_{1}\right|$ : modulus of impedance at the frequency of the first harmonic; ZC: the characteristic impedance modulus; $f$ cross: frequency of the first zero-crossing of impedance phase from negative to positive values; P: postexpiration (plateau between $\mathrm{E}$ and I; with null respiratory flow); I: inspiration; E: expiration. 
Table 2. - Individual values of impedance parameters in $I$ and $E$ as percentage of values in $P$

\begin{tabular}{|c|c|c|c|c|c|c|c|c|}
\hline \multirow{2}{*}{$\begin{array}{l}\text { Dog } \\
\text { No. }\end{array}$} & \multicolumn{2}{|c|}{$R \mathrm{I}$} & \multicolumn{2}{|c|}{$Z_{1}$} & \multicolumn{2}{|c|}{ ZC } & \multicolumn{2}{|c|}{$f_{\text {cross }}$} \\
\hline & I & $\mathrm{E}$ & I & $\mathrm{E}$ & I & $\mathrm{E}$ & $\mathrm{I}$ & $\mathrm{E}$ \\
\hline 1 & 82 & 114 & 111 & 130 & 108 & 127 & 95 & 91 \\
\hline 2 & 91 & 113 & 96 & 99 & 111 & 131 & 97 & 93 \\
\hline 3 & 90 & 105 & 113 & 108 & 114 & 111 & 97 & 93 \\
\hline 4 & 77 & 96 & 114 & 111 & 116 & 106 & 76 & 80 \\
\hline 5 & 83 & 130 & - & - & - & - & - & - \\
\hline
\end{tabular}

For definitions see legend to table 1.

table 1 and 2, it is apparent that changes in RI, ZC and $f$ cross occur during the active phases of respiration (I and E) with respect to the postexpiratory phase. These observations are confirmed by the Hotelling $\mathrm{T}^{2}$-test for multiple comparisons which showed significant modifications of $R \mathrm{I}(\mathrm{p}=0.024), Z \mathrm{C}(\mathrm{p}=0.01)$ and $f_{\text {cross }}(\mathrm{p}=0.007)$ during the active phases. Further details on these changes are shown in figure 4 . The figure illustates mean \pm SE variations of $R \mathrm{I},\left|Z_{1}\right|, Z_{\mathrm{C}}$ and $f_{\text {cross }}$ in $\mathrm{I}$ and $\mathrm{E}$. The univariate statistical analysis of these data indicates: 1) a significant reduction of $R \mathrm{I}$ in $\mathrm{I}, 2)$ a significant increase of ZC both in I and E and 3) a significant decrease of

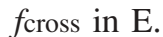

We also recomputed the variations of $R \mathrm{I},\left|Z_{1}\right|, Z \mathrm{C}$ and $f$ cross occurring in $\mathrm{E}$ by following the procedure previously adopted in the literature, namely, by normalizing the data with respect to the other active phase, I, instead of $\mathrm{P}$.

Table 3 shows individual variations in $\mathrm{E}$ as percentage of values in I. In all animals, $R \mathrm{I}$ increases from I to $\mathrm{E}$, whilst both positive and negative changes are found for the other parameters. Mean \pm SEM values in $\mathrm{E}$ as percentage of values in I are shown in figure 5; only $R$ I significantly differs when $\mathrm{E}$ is compared to $\mathrm{I}$.

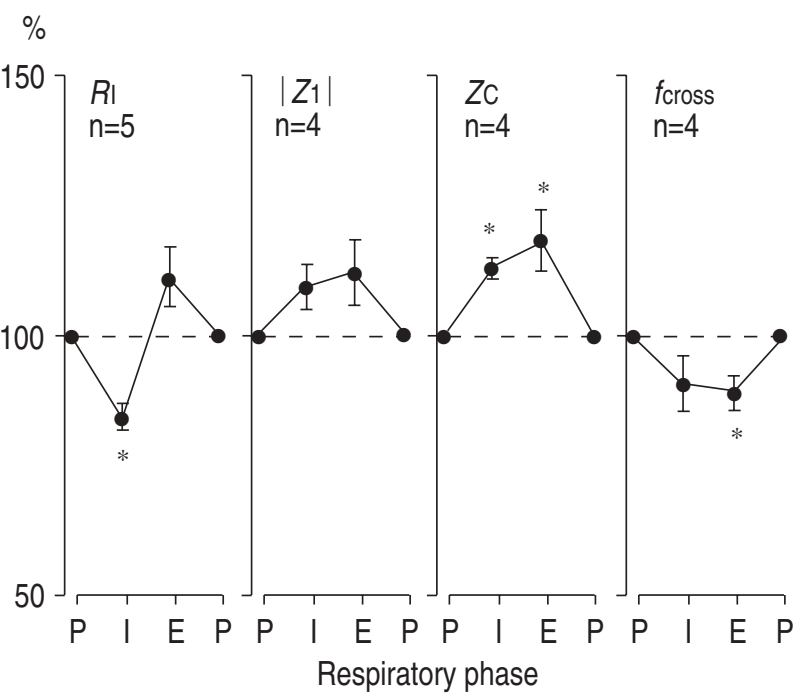

Fig. 4. - Average changes \pm SEM of input resistance $(R \mathrm{I})$, impedance modulus at the frequency of the first harmonic $\left(\left|Z_{1}\right|\right)$, characteristic impedance $(Z \mathrm{C})$, and frequency at phase zero-crossing ( $\left.f_{\text {cross }}\right)$ for the whole group of animals. Values are expressed as percentage of the reference, the $\mathrm{P}$ phase. Hotelling's $\mathrm{T}^{2}$-test showed significant respiratory changes for $R \mathrm{I}, Z \mathrm{C}$ and $f$ cross (see text); for these parameters univariate analyses indicate that: 1) $R$ I decreases in I; 2) ZC rises in I and in $\mathrm{E}$; and 3) $f_{\text {cross }}$ is reduced in $\mathrm{E}$. *: $\mathrm{p}<0.05$ compared to value in $\mathrm{P}$. For further definitions see legend to figure 1 .
Table 3. - Individual values of impedance parameters in $\mathrm{E}$ as percentage of values in I

\begin{tabular}{ccccc}
\hline Dog No. & $R \mathrm{I}$ & $\left|Z_{1}\right|$ & $Z \mathrm{ZC}$ & $f$ CROSS \\
\hline 1 & 141 & 116 & 120 & 98 \\
2 & 125 & 103 & 118 & 96 \\
3 & 117 & 98 & 103 & 102 \\
4 & 125 & 98 & 92 & 106 \\
5 & 160 & - & - & - \\
\hline
\end{tabular}

For definitions see legend to table 1

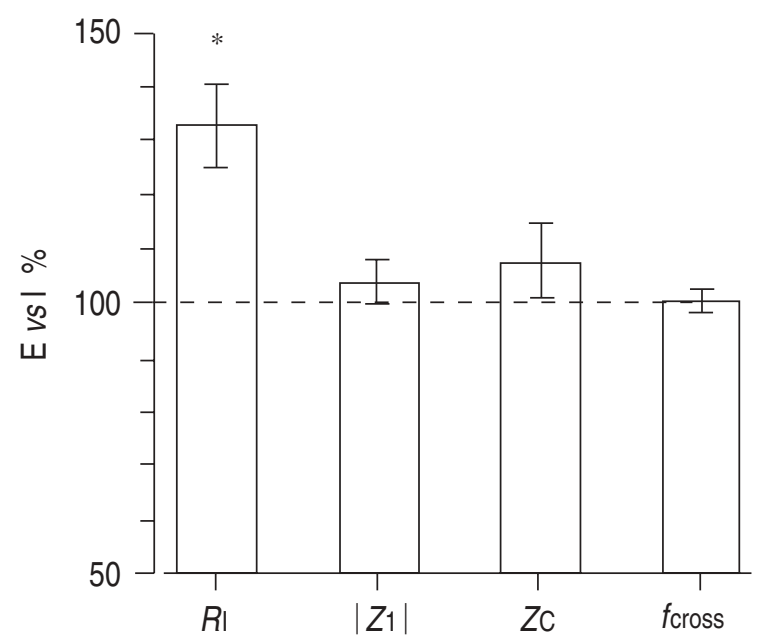

Fig. 5. - Values in $\mathrm{E}$ as percentage of values in $\mathrm{I}$ for $R \mathrm{I},\left|Z_{1}\right|, Z_{\mathrm{C}}$, and $f_{\text {cross; }} *$ : different from the value in $\mathrm{I}(\mathrm{p}<0.05)$. Values are presented as mean \pm SEM. For definitions see legends to figures 1 and 4 .

Mean values (and SEM) of variations in I and in $E$ with respect to $\mathrm{P}$ and in $\mathrm{E}$ with respect to $\mathrm{I}$ are summarized in table 4. All values are expressed as percentage of the reference.

\section{Discussion}

These results indicate, for the first time, that not only the steady component but also the pulsatile components of pulmonary input impedance are significantly modified by the different respiratory phases of spontaneous breathing.

These findings differ from those obtained by other investigators $[4,5]$, probably because in the present study the null respiratory flow phase was considered. Had we simply compared I and E, we also would have found no significant differences in input impedance.

As far as the $0 \mathrm{~Hz}$ component of input impedance is considered $(R \mathrm{I})$, these results are in line with the literature; and the observed respiratory variations of the opposition to steady flow may be explained either by alterations

Table 4. - Variations in I and in E as percentage of values in $\mathrm{P}$, and variation in $\mathrm{E}$ as percentage of values in I

\begin{tabular}{|c|c|c|c|c|}
\hline & $R \mathrm{I}$ & $\left|Z_{1}\right|$ & ZC & $f_{\text {cross }}$ \\
\hline $\mathrm{I} / \mathrm{P} \%$ & $85(2.2)$ & $109(3.5)$ & $112(1.5)$ & $91(4.5)$ \\
\hline $\mathrm{E} / \mathrm{P} \%$ & $112(4.9)$ & $112(5.5)$ & $119(5.0)$ & $89(2.5)$ \\
\hline $\mathrm{E} / \mathrm{I} \%$ & $134(6.7)$ & $104(3.5)$ & $108(5.5)$ & $100(2.0)$ \\
\hline
\end{tabular}

Values are presented as mean over the group, and SEM in parenthesis. For definitions see legend to table 1. 
of pulmonary vascular resistance [7], or by changes in left atrial pressure or pulmonary wedge pressure [4].

The interpretation of data concerning $Z \mathrm{C}$ and $f$ cross is more difficult, since numerous and often interacting factors are involved: e.g. intrathoracic gas volume, blood volume, physical properties of the pulmonary vessels, etc. However, we may venture some guesses. Taylor's analysis of a thin-walled, longitudinally constrained tube (equation 11.16 in [12]) indicates that ZC varies directly with the elastic modulus of arteries: i.e. the stiffer the artery, the higher the characteristic impedance. Moreover, it has been observed that the stiffening of larger pulmonary arteries may be induced by autonomic control of vascular smooth muscles. In particular, it has been demonstrated that $\mathrm{ZC}$ increases in dogs when stiffening of the proximal pulmonary artery is induced by either stimulating the left stellate (sympathetic) ganglion [13, 14], or via the reflex activation of sympathetic outflow induced by haemorrhage [15]. On this basis, the increase of $Z \mathrm{C}$ observed in the present study may reflect changes in arterial stiffening induced by the modulation of sympathetic activity, which has previously been shown to be synchronous with respiration [16].

Evidence of a possible small increase of pulmonary blood volume during inspiration in closed-chest dogs during normal respiration has been reported [17]. It is also known that lung inflation increases the volume of large (extra-alveolar) pulmonary vessels, decreasing the volume of small (alveolar) vessels [18, 19]. A further hypothesis might be, therefore, that the increase of ZC (i.e. stiffness) is due to an enhancement of shear-stress of the proximal pulmonary artery wall, which in turn is secondary to respiratory-synchronous increase of blood volume in extra-alveolar vessels.

Furthermore, even the increase of impedance phase, quantified by the shift of $f_{\text {cross }}$ to lower frequencies, may be due to augmented vessel stiffness. In fact, NichOLS and O'Rourke (page 289 in [12]) showed that in a threeelement model of the arterial tree a reduction of compliance, i.e. a reduction of vessel distensibility, increases the phase shift between pressure and flow.

Despite the increase of $Z \mathrm{C}$ in $\mathrm{I}$ and in $\mathrm{E}$, the present results did not show significant changes of $\left|Z_{1}\right|$, the modulus of impedance at the frequency of the instantaneous heart-rate $f C$. In particular, $\left|Z_{1}\right|$ increased in I and in $\mathrm{E}$ for dogs Nos. 1, 3 and 4, but it did not change in E and slightly decreased in I for dog No. 2 (table 2). However, it must be considered that respiratory changes of $\left|Z_{1}\right|$ might be due not only to impedance changes, but also to $f C$ changes. In this respect, a negligible increase of $f \mathrm{C}$ was observed during $\mathrm{I}(<0.08 \mathrm{~Hz})$ and during $\mathrm{E}$ $(<0.02 \mathrm{~Hz})$ for dogs Nos. 1, 3 and 4 , but a much more substantial increase for dog No. $2(+0.36 \mathrm{~Hz}$ in I and $+0.50 \mathrm{~Hz}$ in E). Since the mean heart rate in the reference condition for dog No. 2 was $2.2 \mathrm{~Hz}$ the increases of $f \mathrm{C}$ during $\mathrm{I}$ and $\mathrm{E}$ might have shifted the "working point" towards the first relative minimum of the impedance modulus. This fact would explain why $\left|Z_{1}\right|$ did not increase in this animal, even if the average impedance modulus between 2 and $12 \mathrm{~Hz}$ increased.

Pulmonary artery input impedance may also change following changes in cardiac output [20] or in pulmonary blood pressure. However, both $P$ pa and $Q^{\prime}$ show different trends in I and in $\mathrm{E}$ with respect to $\mathrm{P}$ (fig. 1), and therefore it is unlikely that these variations might be the main determinant of respiratory changes in ZC and $f_{\text {cross. }}$.

Pulmonary arterial pressure shows less marked respiratory oscillations when it is measured as transmural pressure (i.e. with reference to intrapleuric pressure) rather than as intravascular pressure (i.e. with reference to atmospheric pressure). Therefore, respiratory fluctuations of input impedance might be different if transmural rather than intravascular pressure is used. It is known, however, that the difference between intravascular and transmural pressures, i.e. the intrapleural pressure, varies slowly in beats occurring in a single respiratory phase. Intrapleural pressure is almost constant in $\mathrm{P}$, and increases or decreases following a linear trend in I and in E. During the transition between respiratory phases, the intrapleural pressure is characterized by components at higher frequencies, but beats during the transition between phases were not considered in the present analysis. Therefore, we might expect: 1) consistent discrepancies between intravascular and transmural pressures as far as respiratory changes of the mean value of blood pressure are concerned; but 2) similar respiratory changes of components at frequencies higher than the first harmonic (and therefore similar changes of $Z \mathrm{C}$ and $f_{\text {cross }}$ ). These assumptions are confirmed by experimental data. In fact, intravascular and transmural pressures were simultaneously measured in two animals (dogs Nos. 2 and 3). For these two animals, it could be determined whether and to what extent the use of transmural instead of intravascular pressure might modify the results. The analysis has been performed only on those parameters which showed significant changes, i.e. percentage changes of $R \mathrm{I}$ in I with respect to $\mathrm{P}$, and of $\mathrm{ZC}$ in $\mathrm{I}$ and $\mathrm{E}$ with respect to $\mathrm{P}$, and of $f$ cross in $\mathrm{E}$ with respect to $\mathrm{P}$. Mean \pm SEM values were separately evaluated for the two animals over their respective respiratory cycles. Figure 6 shows ZC and $f_{\text {cross }}$ as obtained by intravascular and transmural pressures. The figure shows that the values obtained by considering intravascular and transmural pressures are slightly different,

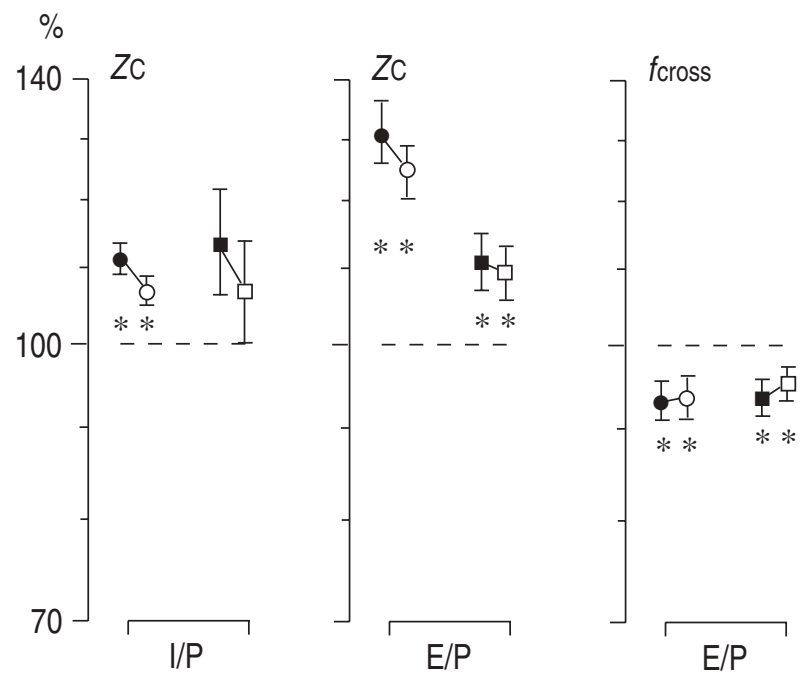

Fig. 6. - Percentage changes of $\mathrm{ZC}$ in $\mathrm{I} v s \mathrm{P}$ and in $\mathrm{E} v s \mathrm{P}$, and of $f_{\text {cross }}$ in $\mathrm{E}$ vs $\mathrm{P}$, in two animals: comparison between pulmonary arterial pressure, $(P$ pa $)$, and pulmonary transmural pressure $\left(P_{\mathrm{tp}}\right)$. Values are presented as mean \pm sem. $\bullet:$ Dog No. $2 P$ pa; $\bigcirc$ : dog No. $2 P$ tp; $\square$ :

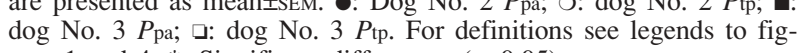
ures 1 and 4. *: Significant differences $(\mathrm{p}<0.05)$. 
but the trends and the results of the statistical evaluation are similar. As expected, this was not the case when $R \mathrm{I}$ was considered (results not shown in the figure). Respiratory changes of $R$ I were much less marked when transmural pressure was used. This suggests that the use of transmural instead of intravascular pressure does not change the statistical conclusions of the study, i.e. the existence of significant respiratory changes in $\mathrm{ZC}$ and fcross.

We also considered the possibility that the observed respiratory changes could be due, at least in part, to the presence of "power leakage" [21]. In fact, if initial and ending values of the $P$ pa or the $Q^{\prime}$ wave differ, then "power leakage" could be present. Leakage produces high frequency spectral components which may influence the evaluation of ZC. Since the difference between start and end of beats falling completely into a single respiratory phase is generally small, it is likely that leakage does not markedly affect the assessment of ZC for these beats. However, ZC and $f$ cross were also computed after leakage removal. Leakage was removed from each $P$ pa and $Q^{\prime}$ wave following a procedure described in the Appendix, and the statistical results for $Z C$ and $f_{\text {cross }}$ did not change. This indicates that leakage did not have any practical influence on our results.

In open-chest, mechanically-ventilated dogs, GRANT et al. [2] found that total pulmonary artery compliance was significantly greater at the start of expiration (SE) than at the start of inspiration (SI). However, it is difficult to compare their findings with ours because: 1) animal preparation was different and inspiration was obtained by applying a positive ventilatory pressure; and 2) impedance parameters were estimated by using a lumped parameter model [22]. GRANT et al. [2] ascribed the increase in compliance from SI to SE to a shift in blood volume from extra-alveolar arteries to alveolar capillaries because of: 1) a decrease of extra-alveolar arterial volume (lung volume being less at SI than at SE); and 2) an increase of alveolar capillary volume, since ventilatory pressure is set to zero at SE. Following the same reasoning, it might be speculated that in the present animal preparation: 1) compliance does not change between I and E because no shift of blood occurs between extra-alveolar and alveolar vessels (the average lung volume is the same in I and $\mathrm{E}$, and no ventilatory pressure is applied in I); and 2) compliance is greater in $\mathrm{P}$, because of the shift of blood volume to extra-alveolar vessels during lung inflation. If these assumptions are valid, the present data are not in contradiction with those obtained by GRANT et al. [2].

In recent years, assessment of $Z(f)$ has been increasingly adopted as a clinical tool to evaluate the interaction between right ventricle and pulmonary vasculature. A rise of characteristic impedance has been observed, for instance, in congestive heart failure [23]; whereas, chronically elevated pulmonary blood flow has been shown to lead to a marked reduction in $Z(f)$ [24]. According to MILNOR et al. [25], the similarity of shape of impedance spectra in man and in dogs leads one to believe that conclusions drawn from studies of pulsatile pressure and flow in the canine pulmonary artery may also apply to human pulmonary vessels. If respiratory driven modulations of impedance also characterize human pulmonary haemodynamics, then procedures for evaluating $Z(f)$, standardized in relation to the different respiratory phases, might make it possible to obtain less variable impedance estimations, or to derive additional information from impedance changes associated with different degrees of lung inflation.

\section{Appendix: leakage removal}

A difference between values at the beginning and at the end of the $P$ pa or the $Q^{\prime}$ waves may produce additional spectral components and cause the so-called "power leakage". This leakage could influence the evaluation of Zc.

Leakage is usually removed by applying data-tapering functions to the signal [21]. A data-taper removes any discontinuity at the beginning and at the end of the data segment considered for the Fourier analysis by weighting the signal with a smooth function. This tapering function decreases from 1 to 0 moving from the centre to the start and the end of the segment. This approach, however, seems to be inappropriate in our case. In fact, data-tapering not only reduces leakage but produces a concomitant distortion of the pressure and flow waves as well. Therefore, data tapers are applicable when the signal length is at least a few times greater than the period of the slower fluctuation considered in the analysis. This means that they can be used when the duration of the
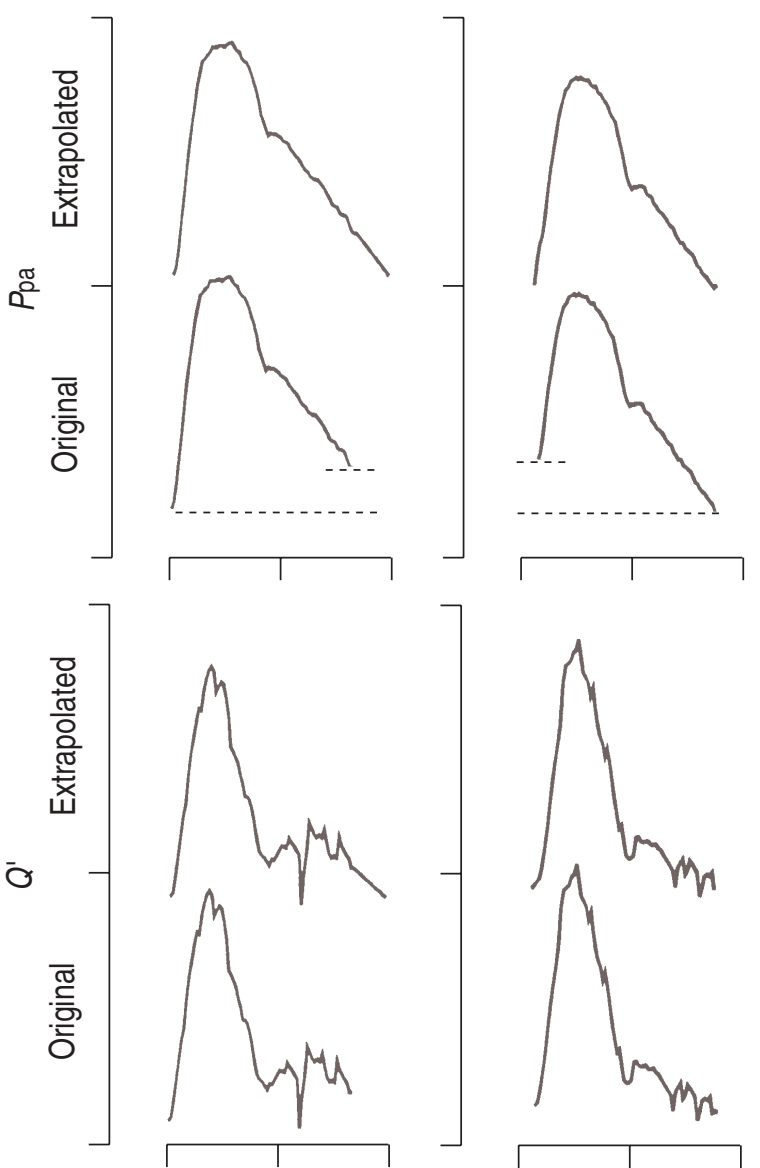

Fig. 7. - Leakage removal by extrapolation. The pulmonary arterial pressure $(P \mathrm{pa})$ wave is linearly extrapolated up to the point where the start and end of the wave are equal. The blood flow velocity $\left(Q^{\prime}\right)$ wave is linearly extrapolated to have the same duration as the $P$ pa wave. 
data segment lasts some beats, but this is not the case when a beat-by-beat analysis is performed.

For this reason, we decided to remove the leakage by using a procedure which produces a minimal distortion in the waveform. The procedure is based on a linear extrapolation of the signal that "completes" the beat in such a way that start and end of the $P$ pa wave are equal. The $Q$ ' wave is also extrapolated to have the same duration as the $P$ pa wave. The procedures is illustrated by the two examples in figure 7 . To better illustrate the procedure, the figure shows beats occurring during a transition between respiratory phases, because these beats are characterized by greater differences between start and end of the $P$ pa wave than beats completely falling into a single respiratory phase.

\section{References}

1. Rustici A, Fogari R, Grossoni M, Tommasini R, Ukmar $\mathrm{G}$, Morpurgo M. Influence of spontaneous respiration on right ventricular systolic time intervals and pulmonary arterial pressures in the dog. In: Daum S, ed. Interaction Between Heart and Lung. New York, Thieme Medical Publ., 1989; pp. 18-24.

2. Grant BJB, Fitzpatrick JM, Lieber BB. Time-varying pulmonary arterial compliance. J Appl Physiol 1991; 70(2): 575-583.

3. Lieber BB, Li Z, Grant BJB. Beat-by-beat changes of viscoelastic and inertial properties of the pulmonary arteries. J Appl Physiol 1994; 76(6): 2348-2355.

4. Murgo JF, Westerhof N. Input impedance of the pulmonary arterial system in normal man: effects of respiration and comparison to systemic impedance. Circ Res 1984; 54: 666-673.

5. Wieland JM Kussmaul WY, Parker HG, Laskey WK. Effects of respiration on pulmonary artery input impedance (Abstract) Clin Res 1986; 34: 865A.

6. Laskey WK, Ferrari WA, Palevsky HI, Kussmaul WG. Pulmonary artery hemodynamics in primary pulmonary hypertension. J Am Coll Card 1993; 21: 406-412.

7. Milnor WR. Hemodynamics. 2nd edn. Baltimore, Maryland, Williams \& Wilkins, 1989.

8. Bendat JS, Piersol AG. Random data: Analysis and measurement procedures. 2nd edn. New York, WileyInterscience, 1986.
9. Bergel DH, Milnor WR. Pulmonary vascular impedance in the dog. Circ Res 1965: 16: 401-415.

10. Holm S. A simple sequentially rejective multiple test procedure. Scand J Stat 1979; 6: 65-70.

11. Fleiss JH. The design and analysis of clinical experiments. New York, John Wiley and Sons, 1986.

12. Nichols WW, O'Rourke MF. McDonald's Blood Flow in Arteries. 3rd edn. London, Edward Arnold, 1990.

13. Pace JB. Sympathetic control of pulmonary vascular impedance in anesthetized dogs. Circ Res 1971; 29: 555-568.

14. Pace JB, Cox RH, Alvarez-Vara F, Karreman G. Influence of sympathetic nerve stimulation on pulmonary hydraulic input power. Am J Physiol 1972; 222: 196-201.

15. Dujardin JPL, Stone DN, Douglas Forcino C, Paul LT, Pieper HP. Effects of blood volume changes on characteristic impedance of the pulmonary artery. Am J Physiol 1982; 242: H197-H202.

16. Ekberg DL, Nerhed C, Wallin BG. Respiratory modulation of muscle sympathetic and vagal cardiac outflow in man. J Physiol Lond 1985; 365: 181-196.

17. Harris $\mathrm{P}$, Health D. The human pulmonary circulation. 2nd edn. Edinburgh, Churchill Livingstone, 1977.

18. Macklin CC. Evidences of the capacity of the pulmonary arteries and veins of dogs, cats and rabbits during inflation of the freshly excised lung. Rev Can Biol 1946; 5: 199-282.

19. Howell JBL, Permutt S, Proctor DF. Riley RL. Effect of inflation of the lung on different parts of the pulmonary vascular bed. J Appl Physiol. 1961; 16: 71-76.

20. Grant BJB, Canty JM. Effects of cardiac output on pulmonary hemodynamics. Respir Physiol 1989; 76: 303-318.

21. Brigham EO. The Fast Fourier Transform. Englewood Cliffs, NJ, Prentice-Hall, 1974.

22. Grant BJB, Paradowsky LJ. Characterization of pulmonary arterial input impedance with lumped parameter models. Am J Physiol 1987; 252 (Heart Circ Physiol 21): H585-H593.

23. Kussmaul WG, Altschuler JA, Matthai WH, Laskey WK. Right ventricular-vascular interaction in congestive heart failure: importance of low-frequency impedance. Circulation 1993; 88: 1010-1015.

24. Hopkins RA, Hammon JW, McHale PA, Smith PK, Anderson RW. Pulmonary vascular impedance analysis of adaptation to chronically elevated blood flow in the awake dog. Circ Res 1979; 45: 267-274.

25. Milnor WR, Conti RC, Lewis KB, O'Rourke MF. Pulmonary arterial pulse wave velocity and impedance in man. Circ Res 1969; 25(6): 637-649. 